\title{
Thylakoid fatty acid composition and response to short-term cold and heat stress in high-latitude Symbiodiniaceae
}

\author{
Clinton A. Oakley ${ }^{1}\left({ }^{\circ} \cdot\right.$ Stefanie Pontasch $^{1} \cdot$ Paul L. Fisher $^{1} \cdot$ Shaun P. Wilkinson $^{1}$. \\ Robert A. Keyzers ${ }^{2}$. Thomas Krueger ${ }^{1,3}$ - Sophie Dove ${ }^{4}$ - Ove Hoegh-Guldberg ${ }^{4}$. \\ William Leggat ${ }^{5} \cdot$ Simon K. Davy ${ }^{1}$
}

Received: 29 March 2021 / Accepted: 15 January 2022 / Published online: 2 February 2022

(C) The Author(s) 2022

\begin{abstract}
Coral reefs are restricted to warm waters, but are increasingly threatened by coral bleaching induced by sustained high sea surface temperatures. Coral endosymbiont thermal resilience has been proposed to depend, at least in part, on the lipid composition of their thylakoid membranes, which influences photosynthetic performance under sub- and super-optimal thermal conditions in photosynthetic organisms. Dinoflagellate symbionts of highlatitude coral reefs experience large seasonal changes in temperature, requiring a wide range of thermal tolerance, and so the thermal responses of their membrane lipids are of particular interest. Using gas chromatography-mass spectrometry, we investigated the composition and response to high- and low-temperature stress of thylakoid fatty acids of dinoflagellate symbionts isolated from corals of Lord Howe Island, the world's southernmost coral reef. We detected genotype-specific differences in the quality of thylakoid fatty acids of two Cladocopium ITS2 consortia/ genotypes, $\mathrm{C} 100 / 118$ and $\mathrm{C} 111 *$, common local symbionts
\end{abstract}

Topic Editor Mark Vermeij

Simon K. Davy

simon.davy@vuw.ac.nz

1 School of Biological Sciences, Victoria University of Wellington, Wellington, New Zealand

2 School of Chemical and Physical Sciences, Victoria University of Wellington, Wellington, New Zealand

3 Present Address: Department of Biochemistry, University of Cambridge, Cambridge, UK

4 School of Biological Sciences, The University of Queensland, St Lucia, QLD, Australia

5 School of Environmental and Life Sciences, The University of Newcastle, Callaghan, NSW, Australia of the corals Pocillopora damicornis and Porites heronensis. The capability to adjust thylakoid fatty acid composition in response to temperature differed between distinct Cladocopium genotypes, and between the same Cladocopium consortium (C100/118) in the same coral species from different locations. Fatty acid adjustments were highly similar in response to short-term cold and heat stresses, with substantial increases in long-chain polyunsaturated fatty acids and a corresponding increase in the ratio of unsaturated to saturated fatty acids, but these changes did not correlate with the quantum yield of photosystem II. The response of thylakoid fatty acid composition to changes in temperature was a function of symbiont genotype, coral host species and, potentially, environmental history. Our data suggest the existence of common responses to high- and low-temperature stresses and that thylakoid fatty acid saturation is an unreliable predictor of photosystem efficiency under thermal stress in dinoflagellate symbionts.

Keywords Coral bleaching - Fatty acids . Photophysiology · Thylakoids · Symbiodiniaceae

\section{Introduction}

The mutualistic association of symbiotic dinoflagellates (family Symbiodiniaceae) and their coral hosts is ecologically important but very sensitive to environmental perturbation (Davy et al. 2012; Hughes et al. 2018). Extreme changes in temperature, often associated with high light intensity, can induce cellular stress in either symbiotic partner followed by bleaching, defined as reductions of symbiont pigments or symbiont density (Hoegh-Guldberg 1999; Hughes et al. 2017; Oakley and Davy 2018). 
Although research has appropriately emphasized the adverse effects of high sea surface temperature anomalies in coral bleaching, low-temperature events and associated bleaching and mortality have been reported in several reef systems (Hoegh-Guldberg and Fine 2004; LaJeunesse et al. 2010; Kemp et al. 2011).

Bleaching is frequently associated with a decline of photosynthetic function and carbon fixation in the algal symbionts (Warner et al. 1996; Warner and Suggett 2016). In the Symbiodiniaceae, acclimation to high temperature requires adjustments to the thermal stability of photosynthetic membranes (Ulstrup et al. 2009). The composition of fatty acids (FAs) in the chloroplast thylakoids of higher plants and algae affects membrane fluidity, light harvesting, electron transport, ion barrier performance and the function or turnover of thylakoid membrane-associated proteins (Mullineaux and Kirchhoff 2009). Photosynthetic microorganisms have the capability to adjust membrane lipid composition in response to environmental change, including the levels of FA unsaturation, chain length or branching (Iba 2002; Morgan-Kiss et al. 2006). Thermally driven changes in thylakoid membrane fluidity can uncouple light harvesting and photochemistry, suppressing NADPH and ATP synthesis and resulting in concomitant increased production of reactive oxygen species (ROS) (Tchernov et al. 2004). Excess ROS are cytotoxic compounds which induce widespread cellular stress and can induce coral mortality or expulsion of symbiont cells (Oakley and Davy 2018; Rosset et al. 2021).

The sensitivity of dinoflagellate photosynthetic membranes to high temperatures, as defined by thylakoid integrity, photochemical function, and chloroplast production of ROS, has been linked to the level of FA unsaturation (Tchernov et al. 2004). It is controversial, however, whether FA composition could be generally diagnostic of thermally robust Symbiodiniaceae cells (Díaz-Almeyda et al. 2011). FA profiles of Symbiodiniaceae and other dinoflagellates have previously been described (Bishop and Kenrick 1980; Mansour et al. 1999; Zhukova and Titlyanov 2006), and thylakoid membrane melting points vary between Symbiodiniaceae species (Mansour et al. 2018). In symbiosis, changes occur in FA composition in the corals Acropora aspera and Montipora digitata and their symbionts in response to elevated temperatures (Papina et al. 2007; Hillyer et al. 2017b), as well as the synthesis and mobilization of FAs in the model symbiotic cnidarian Exaiptasia diaphana (Hillyer et al. 2017a). Whether the FA composition of thylakoid membranes, in particular, may adjust to sub- and super-optimal temperatures has not been investigated in Symbiodiniaceae in hospite.

The family Symbiodiniaceae is composed of eleven described genera and several undescribed genera-level lineages (LaJeunesse et al. 2018, 2021; Nitschke et al.
2020; Pochon and LaJeunesse 2021). This diversity is reflected by differences in cellular morphology, physiology, and bleaching responses (Berkelmans and van Oppen 2006; Hennige et al. 2008; Pettay et al. 2015; Suggett et al. 2015; Swain et al. 2017) as well as differential translocated compounds and effects on host physiology (Matthews et al. 2017, 2018; Sproles et al. 2019). Cnidarian-dinoflagellate symbioses are geographically restricted by seasonal thermal minima, and beyond these ranges may be supplanted by other algal symbionts (e.g. Trebouxiophyceae) in noncoral hosts (Dimond et al. 2013). Endemic members of Cladocopium sp., ITS2 genotypes C111* and C100/C118, have been identified in the high-latitude coral reefs of Lord Howe Island ( $\left.\mathrm{LHI} ; 31^{\circ} 33^{\prime} \mathrm{S}, 159^{\circ} 05^{\prime} \mathrm{E}\right)$. These algae associate with the corals Porites heronensis $\left(\mathrm{C} 111^{*}\right)$ and Pocillopora damicornis (C100/C118), respectively (Wicks et al. 2010a, 2010b). C100/118 has been demonstrated to be susceptible to thermal bleaching, while $\mathrm{C} 111^{*}$ is more tolerant (Pontasch et al. 2017). These high-latitude symbioses are ideal for studying the effects of both high- and low-temperature stress due to their relatively low sea surface temperature maxima $\left(26.5^{\circ} \mathrm{C}\right)$ and minima $\left(17^{\circ} \mathrm{C}\right)$ over the past decade (www.data.aims.gov.au).

The primary objective of this study was to compare the composition of thylakoid FAs in Cladocopium C100/C118 and $\mathrm{C} 111^{*}$ genotypes harboured by the corals Pocillopora damicornis and Porites heronensis, respectively, before and after exposure to short-term heat and cold stress. In doing so, we can investigate the links between thylakoid FA composition and photosynthetic performance under thermal stress. We hypothesize that FA composition of the thylakoid membrane may contribute to the documented differential thermal susceptibility between symbiont genotypes, and that the thylakoid membrane will undergo distinct changes in FA composition under high- and lowtemperature stress. If confirmed, FA composition may be predictive of photosynthetic performance and bleaching susceptibility.

\section{Materials and methods}

\section{Sampling and experimental procedure}

In March 2011, three fragments each from four colonies of Pocillopora damicornis and Porites heronensis were sampled from the lagoon site of Sylph's Hole $\left(\mathrm{S} 31^{\circ} 31^{\prime} 24.9^{\prime \prime}, \mathrm{E} 159^{\circ} 03^{\prime} 26.1^{\prime \prime}\right)$ and from each of four colonies of $P$. damicornis from the lagoon site of Stephen's Hole (S31 $32^{\prime} 10.9^{\prime \prime}$, E159 $\left.03^{\prime} 08.3^{\prime \prime}\right)$. Fragments were each approximately $10 \mathrm{~cm}$ long (P. damicornis) or $10 \mathrm{~cm}^{2}$ area (P. heronensis). Sylph's Hole differs from Stephen's Hole in that turbidity is approximately 1.8 -fold greater (Wicks 
et al. 2010b). All fragments were taken from a depth of 0.5-3 $\mathrm{m}$ at low tide from the top of the colony to ensure that coral fragments had experienced the same light history. Immediately after sampling, fragments from each coral colony were divided, for a total of 16 coral explants of $\sim 2 \mathrm{~cm}$ length each. One of the explants was preserved in $\mathrm{NaCl}$-saturated $20 \%$ dimethyl sulfoxide buffer for symbiont genotyping. The remaining 15 explants per colony were maintained in $50 \mathrm{~L}$ tanks (one tank per treatment) at a temperature of $\sim 24{ }^{\circ} \mathrm{C}$ and a flow rate of $\sim 80 \mathrm{~L}$ $\mathrm{h}^{-1}$ unfiltered, aerated seawater from the lagoon. Given the lack of replicate treatment tanks, "tank effects" cannot be discounted. Natural irradiance was reduced with shade cloth to an average daily maximum of $1240 \mu \mathrm{mol}$ quanta $\mathrm{m}^{-2} \mathrm{~s}^{-1}$.

After four days of acclimation to these conditions, the explants were evenly divided (five fragments per tank) between three temperature treatments: $16^{\circ} \mathrm{C} \pm 0.1$ (mean \pm standard error), corresponding to $2{ }^{\circ} \mathrm{C}$ below the monthly mean temperature minimum; $24{ }^{\circ} \mathrm{C} \pm 0.1$ as a control; or $28^{\circ} \mathrm{C} \pm 0.1$, which is $4^{\circ} \mathrm{C}$ above the monthly mean temperature maximum (NOAA Coral Reef Watch). Tanks were adjusted to the designated temperature over 6-10 h. These thermal treatments lasted four days. One day prior to beginning the thermal treatment and on the final day, between 1400 and 15:00 h, two explants from each coral colony were frozen in liquid nitrogen and stored at $-80{ }^{\circ} \mathrm{C}$ until analysis. Temperature and irradiance were monitored continuously during the experiment by a submersible logger (HOBO, Onset Corp., USA).

\section{Symbiont genotyping}

DNA was isolated from preserved coral tissue using the procedures of Stat et al. (2009). Symbiodiniaceae ITS2 was amplified by PCR using the primers itsDINO (Pochon et al. 2001) and Its2CLAMP (LaJeunesse 2002). Amplicons were separated using denaturing gradient gel electrophoresis (Pontasch et al. 2017) and the resulting dominant bands re-amplified and sequenced (Macrogen, South Korea) in forward and reverse directions with the primer set ITSDINO and ITS2REVint (5'-CCATATGCTTAAGTTCAGCGGG-3') to confirm symbiont ITS2 identity.

\section{Sample preparation}

Frozen coral explants were airbrushed in TB buffer (100 mM Tris- $\mathrm{HCl} \mathrm{pH} 8.0,2 \mathrm{mM} \mathrm{MgCl}_{2}, 2 \mathrm{mM}$ EDTA, $1 \mathrm{mM}$ phenylmethyl sulfonyl fluoride), and the homogenates of two explants per colony and time point were pooled. The combined homogenate was centrifuged at $800 \times \mathrm{g}$ for $5 \mathrm{~min}$, the algal pellet washed four times with
TB buffer and then re-suspended in $16 \mathrm{~mL} \mathrm{~TB}$ buffer. From this re-suspension, $11 \mathrm{~mL}$ was used for cell lysis and enrichment of photosynthetic membranes, and the remainder of the homogenate was stored at $-80{ }^{\circ} \mathrm{C}$ in five aliquots of $1 \mathrm{~mL}$ each.

\section{Fractionation of photosynthetic membranes}

Cell lysis and fractionation followed a modified protocol of Diaz-Almeyda et al. (2011). Cells were broken by two passes through a hydraulic French press at $6.9 \mathrm{kPa}$. Analysis by light microscopy showed that less than $5 \%$ of cells remained intact after two passes. After centrifugation at $500 \times \mathrm{g}$ for $10 \mathrm{~min}$ to remove unbroken cells, the supernatant was pelleted by ultracentrifugation at $50,000 \times \mathrm{g}$ for $60 \mathrm{~min}$ at $4{ }^{\circ} \mathrm{C}$. The cell pellet was re-suspended in $1 \mathrm{~mL}$ TB buffer, loaded onto a discontinuous sucrose gradient $(5,10,15$, and $20 \%)$ and centrifuged at $50,000 \times \mathrm{g}$ for $3 \mathrm{~h}$ at $4{ }^{\circ} \mathrm{C}$ to separate cell components and isolate photosynthetic membranes. The fraction containing the membranes was re-suspended in $10 \mathrm{~mL}$ TB buffer and stored at $-80{ }^{\circ} \mathrm{C}$. As thylakoids represent the largest part of membranes in photosynthetic cells, this fraction is referred to as 'membranes enriched in thylakoids'.

\section{Lipid extraction and derivatization}

Lipids of membranes enriched in thylakoids were extracted using the modified Folch method (1957). All solvents contained $0.002 \%$ butylated hydroxytoluene to suppress autoxidation of FAs (Díaz-Almeyda et al. 2011). At all times, crude extracts, lipid extracts and FAs were processed and stored under nitrogen gas.

Membranes enriched in thylakoids were lyophilized under vacuum at $-60{ }^{\circ} \mathrm{C}$ overnight. Lipids were extracted twice in a total volume of $4 \mathrm{~mL}$ dichloromethane/methanol (2: $1, \mathrm{v} / \mathrm{v})$ for $18 \mathrm{~h}$ at $4{ }^{\circ} \mathrm{C}$ with gentle agitation of $25 \mathrm{rpm}$ in the presence of the internal standard C19:0 methyl ester (methyl nonadecanoate). Proteins were precipitated by the addition of $800 \mu \mathrm{L} 0.9 \% \mathrm{NaCl}$, resulting in phase separation. The organic phase, containing the lipid fraction, was recovered and transferred to a glass tube. Solvents were evaporated at $40{ }^{\circ} \mathrm{C}$ under nitrogen. Fatty acid methyl esters (FAMEs) were synthesized by transesterification with $2 \%$ concentrated $\mathrm{H}_{2} \mathrm{SO}_{4}$ in methanol/toluene (20: 1, $\mathrm{v} / \mathrm{v}$ ) for $2 \mathrm{~h}$ at $90{ }^{\circ} \mathrm{C}$. FAMEs were extracted with hexane/ $\mathrm{NaCl}(5 \%)(2: 1, \mathrm{v} / \mathrm{v})$ for $15 \mathrm{~h}$ at $-80{ }^{\circ} \mathrm{C}$. Extracted FAMEs were stored under nitrogen at $-20{ }^{\circ} \mathrm{C}$ before gas chromatography-mass spectrometry.

The gas chromatograph (QP2010-Plus, Shimadzu) was fitted with a RTX-5SilMS column $(30 \mathrm{~m} \times 0.25 \mathrm{~mm}$ i.d. $\times 0.25 \mu \mathrm{m}$ film thickness) and attached to an electron impact mass spectrometer operating at $70 \mathrm{eV}$ in positive 
ion mode, scanning from $m / z, 40-600$ at $3.33 \mathrm{~Hz}$. Samples $(1 \mu \mathrm{L})$ were introduced with split injection (20:1) at an injector temperature of $260{ }^{\circ} \mathrm{C}$ using $\mathrm{He}$ as the carrier gas at a linear velocity of $1.58 \mathrm{~mL} \mathrm{~min}^{-1}$ at constant flow. Each sample was injected with an initial oven temperature of $50{ }^{\circ} \mathrm{C}$ for $2 \mathrm{~min}$, followed by a ramp of $4{ }^{\circ} \mathrm{C} \min ^{-1}$ to $190{ }^{\circ} \mathrm{C}$, held for $10 \mathrm{~min}$, followed by a second gradient of $3{ }^{\circ} \mathrm{C} \min ^{-1}$ to $240{ }^{\circ} \mathrm{C}$. FAMEs were identified by comparison of both retention time and mass spectra with mixtures of known standards and were quantified by comparing the respective peak areas to the peak area of the internal standard (Díaz-Almeyda et al. 2011). The total lipid concentration was calculated from the sum of total FAMEs resolved, with the FAMEs presented as relative percentages of total lipids.

\section{Symbiont cell density and chlorophyll concentration}

Symbiont cell density was determined by six replicate counts with a haemocytometer and standardized to cells $\mathrm{cm}^{-2}$ coral surface area as determined using the paraffin wax method (Stimson and Kinzie 1991). Chlorophyll was extracted from a pellet of $1 \mathrm{~mL}$ symbiont cells using $90 \%$ acetone for $24 \mathrm{~h}$ at $4{ }^{\circ} \mathrm{C}$. Chlorophyll $a$ and $c_{2}$ concentrations were determined by spectrophotometry using the equation of Jeffrey and Humphrey (1975) and the corrected coefficients for dinoflagellates (Ritchie 2006).

\section{Chlorophyll fluorescence}

Chlorophyll fluorescence was measured using an imaging pulse amplitude modulated fluorometer (Walz, Germany). The maximum quantum yield of photosystem II $\left(F_{v} / F_{m}\right)$ was measured daily at $1900 \mathrm{~h}$, and the effective quantum yield of photosystem II $\left(\Delta F_{v} / F_{m}{ }^{\prime}\right)$ and non-photochemical quenching (NPQ) were measured daily at noon. Corals were dark-acclimated for $20 \mathrm{~min}$ prior to measurement of $\mathrm{F}_{\mathrm{m}}$. After this first saturation pulse, corals were exposed to $186 \mu \mathrm{mol}$ quanta $\mathrm{m}^{-2} \mathrm{~s}^{-1}$ actinic light for $180 \mathrm{~s}$, after which a second saturation pulse was applied to determine $F_{m}{ }^{\prime}$ and light-acclimated $\Delta F_{v} / F_{m}{ }^{\prime}$. The saturating irradiance was not measured and may be greater than $186 \mu \mathrm{mol}$ quanta $\mathrm{m}^{-2} \mathrm{~s}^{-1}$; previously measured values in $P$. damicornis range from 47 to $233 \mu \mathrm{mol}$ quanta $\mathrm{m}^{-2} \mathrm{~s}^{-1}$ (Ulstrup et al. 2006; Schrameyer et al. 2014). The resulting NPQ calculations may therefore be an underestimate. The fluorometer settings were measuring intensity $=3$, saturation intensity $=8$; saturation width $=0.8 ;$ gain $=1\left(F_{v} / F_{m}\right.$ at 19:00 h) or $3\left(\Delta F_{v} / F_{m}{ }^{\prime}\right.$ and NPQ at noon).

NPQ is calculated as

$N P Q=\left(F_{m}-F_{m}\right) / F_{m}$
Maximum midday excitation pressure over PSII $\left(Q_{m}\right)$ (Iglesias-Prieto et al. 2004) was calculated as in Fisher et al. (2012):

$Q_{m}=1-\left(\left[\Delta F_{v} / F_{m}\right]\right.$ at noon $/\left[F_{v} / F_{m}\right]$ at dawn of day 0$)$

\section{Statistical analyses}

Data were analysed using SPSS (v20.0, IBM Corp.). Repeated measures analysis of variance (rmANOVA) and post hoc pairwise comparison with Bonferroni adjustment were used to test $(p \leq 0.05) F_{v} / F_{m}, Q_{m}$, and NPQ. Data were arcsine transformed $\left(F_{v} / F_{m}\right)$ or $\log$ transformed $\left(Q_{m}\right)$ to meet assumptions of normality. When assumptions of equality of the variances were violated, the GreenhouseGeisser correction is reported. rmANOVA with Bonferroni adjusted post hoc pairwise comparisons or univariate ANOVA with post hoc Tukey HSD tests was used to test effects on symbiont density, pigment concentration and arcsine-transformed FA parameters. When assumptions of normality were violated, statistical results were confirmed using the nonparametric Kruskal-Wallis test and post hoc pairwise comparisons with Bonferroni-Dunn adjustments.

\section{Results}

\section{Symbiont genotyping}

Pocillopora damicornis from both sampling locations hosted a mixed symbiont ITS2 assemblage of C100 and C118. Porites heronensis from Sylph's Hole harboured ITS2 type C111*. The ITS2 sequences are available from NCBI, accessions KF194189 (C100/118) and KF194186 (C111*).

\section{Bleaching descriptors}

On day 0 , symbiont cell density and chlorophyll concentrations (on both a per cell basis and coral surface area basis) were approximately twofold greater in $P$. heronensis than P. damicornis from both sampling locations (Fig. 1). Symbiont cell density, chlorophyll concentration and chl $c_{2} / a$ ratio after four days of temperature exposure showed no difference to the beginning of the experiment in all treatments in both coral (Fig. 1).

\section{Chlorophyll fluorescence}

$F_{v} / F_{m}$ decreased markedly at $16^{\circ} \mathrm{C}$, but not $28^{\circ} \mathrm{C}$, by $54-68 \%$ in all symbiont genotypes after four days (Fig. 2ac). This corresponded with an increase in $Q_{m}$ of $65-85 \%$ in 

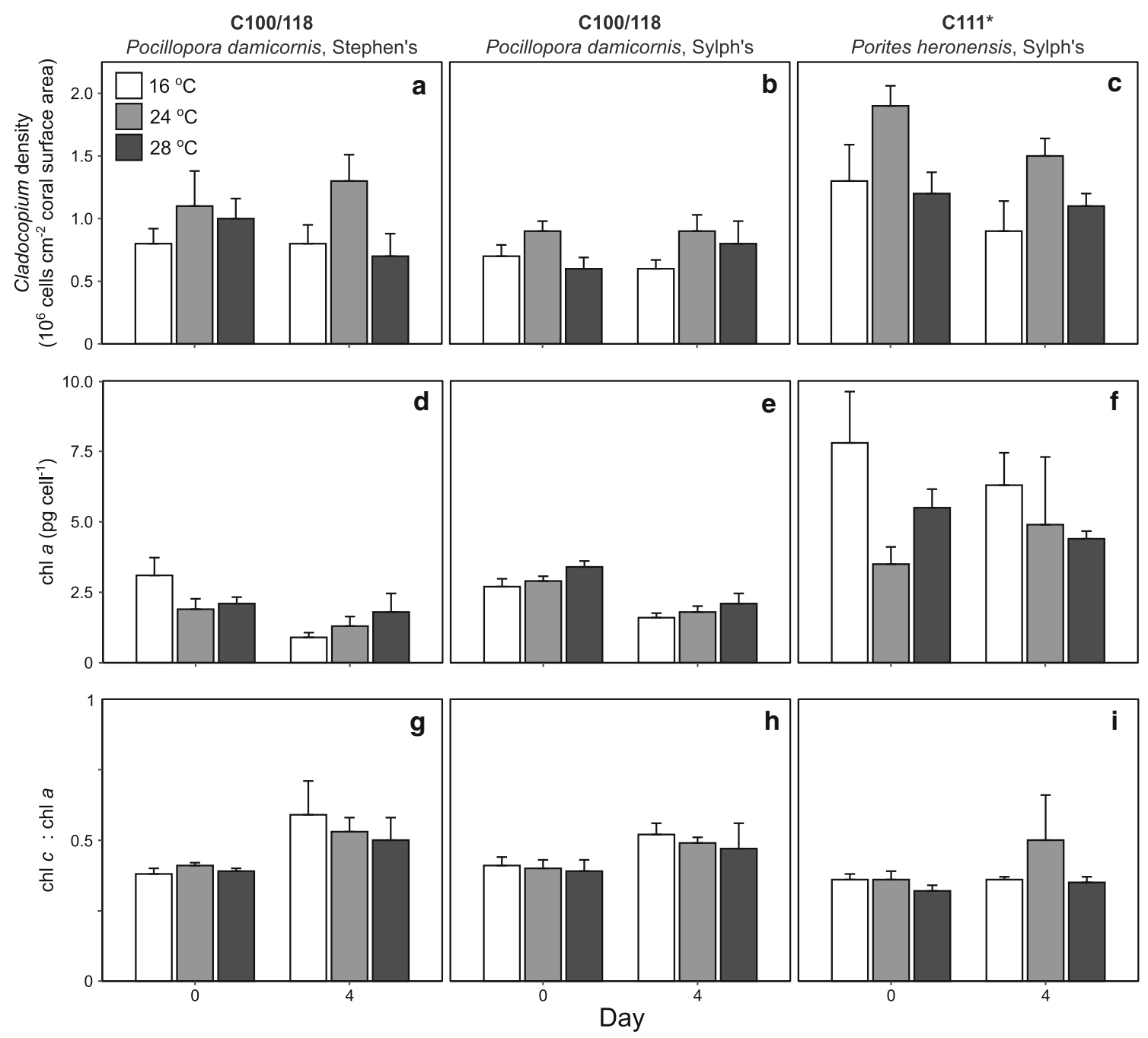

Fig. 1 Symbiont cell density (a-c), chlorophyll $a$ concentration (d-f), and chl $c_{2}$ :chl $a$ ratio $(\mathbf{g}-\mathbf{i})$ of Cladocopium sp. isolated from Pocillopora damicornis and Porites heronensis from reefs of Lord Howe Island on day 0 and day 4 of thermal treatments. Values are means \pm S.E, $n=4$

all symbiont genotypes under cold stress (Fig. 2d-f). NPQ was suppressed by $40 \%$ after four days of cold stress in C111* (Fig. 2g-i).

\section{Thylakoid fatty acids}

While the total amount of thylakoid-enriched FAs was similar between species (20.8-25.6 pg cell $\left.^{-1}\right)$, the composition and ratios of FAs differed between Cladocopium C100/118 and those of C111* (Table 1) before beginning the thermal treatments. On day 0 , the relative proportion of saturated FAs ( $\Sigma$ SFA) in C111* was lower and that of mono-unsaturated and polyunsaturated FAs ( $\Sigma$ MUFA and $\Sigma$ PUFA) was higher, compared with C100/C118 (Table 1). This resulted in a higher baseline ratio of unsaturated FAs to saturated FAs (UFA:SFA) in C111* compared with C100/118 (Fig. 3a-c). C111* membranes enriched in thylakoids had a significantly lower relative content of short chain FAs (C14 and C16) and a higher content of long-chain FAs (C18, C20, and C22) than did C100/C118 on day 0 (Fig. $4 \mathrm{a}-\mathrm{c}$, Table 1).

The two symbiont genotypes also varied in the response of their thylakoid FA chain length compositions and FA saturation to thermal extremes. C100/C118 Stephen's maintained its FA chain length composition over time at all temperatures (Fig. 4a,d), while in C100/C118 Sylph's, the long-chain FA C22 increased at $16{ }^{\circ} \mathrm{C}$, decreased at $24{ }^{\circ} \mathrm{C}$ and was unchanged at $28^{\circ} \mathrm{C}$. FAs with shorter chains remained constant over time. In $\mathrm{C} 111^{*}$, there was a trend towards fewer shorter-chain FAs $(\mathrm{C} 16, \mathrm{C} 18)$ and increases in longer-chain FAs $(\mathrm{C} 20, \mathrm{C} 22)$ at thermal extremes (Fig. 4f). The short chain FA C14 was relatively stable over time at all temperatures. The total content of thylakoid FAs was not affected by temperature over time. 


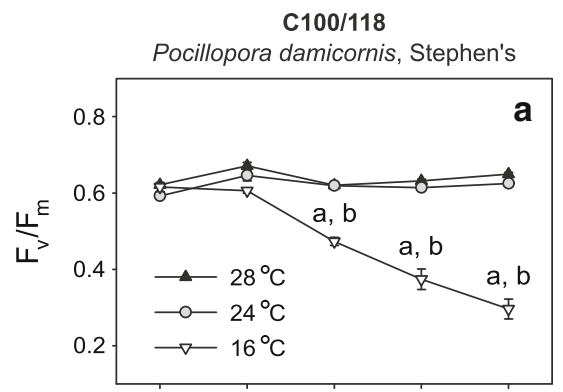

C100/118

Pocillopora damicornis, Sylph's
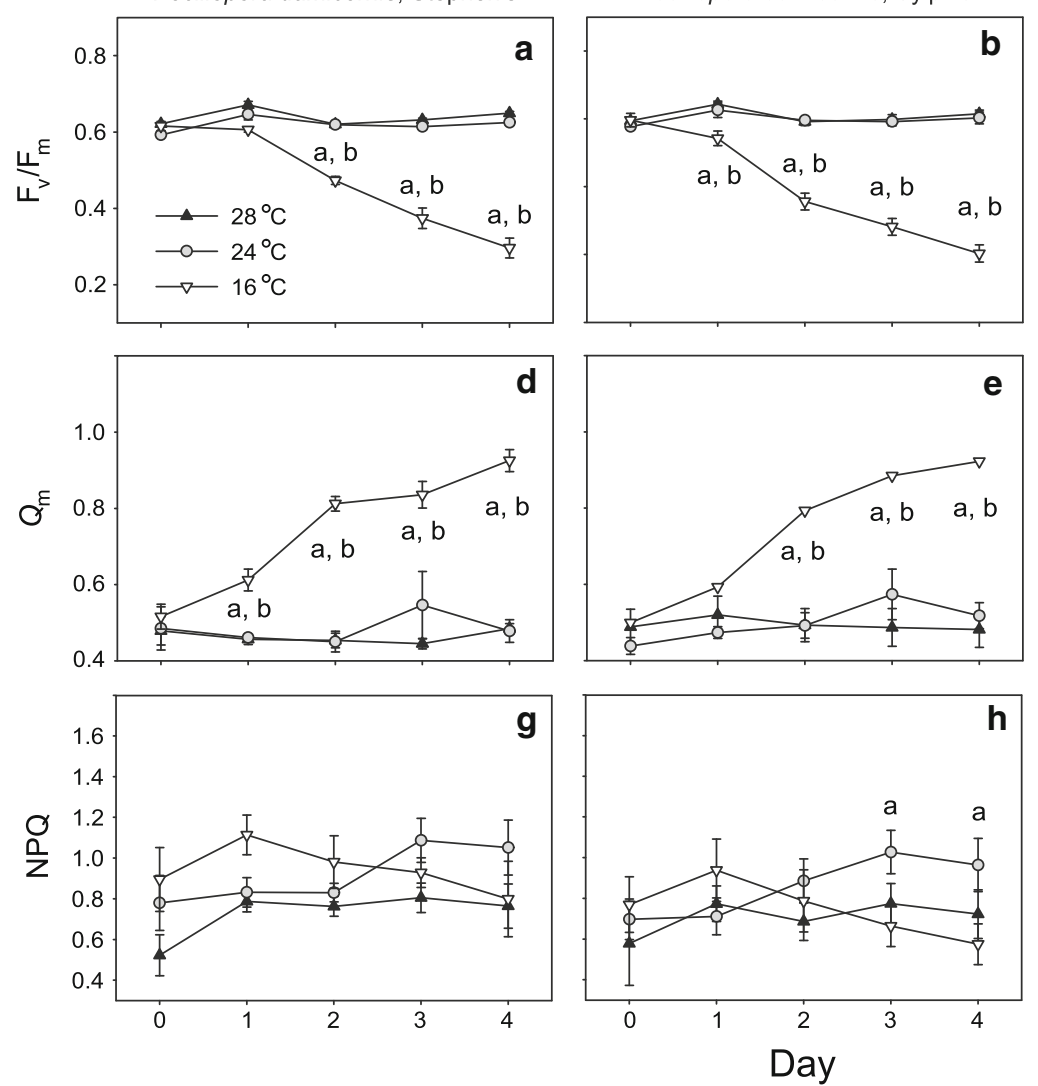

C111*

Porites heronensis, Sylph's
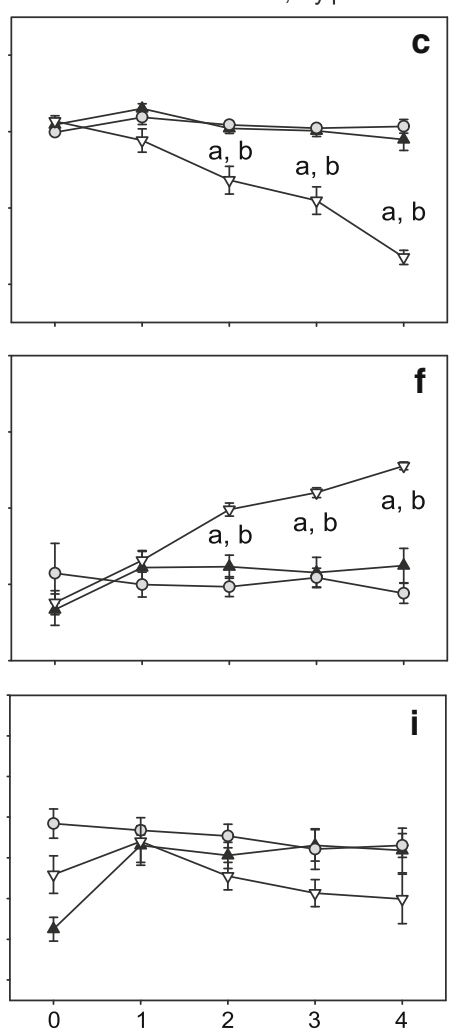

differences are a $16{ }^{\circ} \mathrm{C} v s .24{ }^{\circ} \mathrm{C}$, b $16{ }^{\circ} \mathrm{C} v s .28{ }^{\circ} \mathrm{C}$, and c $24{ }^{\circ} \mathrm{C} v s$. $28^{\circ} \mathrm{C}(p<0.05$, rmANOVA and pairwise comparison with Bonferroni correction) quantum yield of photosystem II $\left(\mathrm{F}_{\mathrm{v}} / \mathrm{F}_{\mathrm{m}} ; \mathbf{a}-\mathbf{c}\right)$, maximum midday excitation pressure over PSII $\left(Q_{\mathrm{m}} ; \mathbf{d}-\mathbf{f}\right)$ and non-photochemical quenching (NPQ; g-i). Values are means \pm S.E, $n=4$. Significant

\section{Discussion}

We found variation in the baseline FA composition of thylakoid-enriched membranes and their response to thermal stress between distinct Cladocopium genotypes. Cladocopium C100/C118 in P. damicornis from Stephen's Hole maintained a stable thylakoid lipid composition over time under all temperature treatments, while $\mathrm{C} 100 / \mathrm{C} 118$ in $P$. damicornis from Sylph's Hole adjusted the quality of photosynthetic membranes in response to exposure to $16{ }^{\circ} \mathrm{C}$ and $24{ }^{\circ} \mathrm{C}$, but not $28{ }^{\circ} \mathrm{C}$ (Fig. 4). C111* extensively remodelled FAs in membranes enriched in thylakoids at all temperature treatments. This agrees with earlier findings, which demonstrated species-specific differences in the composition of total cellular FAs (Bishop and Kenrick 1980; Mansour et al. 1999; Zhukova and Titlyanov 2003) and FAs of photosynthetic membranes (Díaz-Almeyda et al. 2011) in the Symbiodiniaceae. It is not known whether the composition of thylakoid FAs is a primary determinant of thermal robustness or sensitivity of PSII in the Symbiodiniaceae (Tchernov et al. 2004; Díaz-
Almeyda et al. 2011), and therefore whether it is central to the loss of photosynthetic efficiency that often accompanies thermal bleaching (Takahashi et al. 2013). Symbiont genotypes or consortia in the current study varied in their flexibility to modulate thylakoid FA quality under shortterm cold and heat stress, but this flexibility was neither a sole function of symbiont species nor dependent on host species. Both high- and low-temperature stress induced an increase in the relative content of long-chain polyunsaturated fatty acids in Cladocopium $\mathrm{C} 111^{*}$, but only a limited response in C100/C118 (Fig. 4). These modifications were not related to impairment of PSII fluorescence at a given temperature. These results indicate that, in thermally stressed Cladocopium cells, photosynthetic performance (estimated by chlorophyll fluorescence of PSII) is not dependent on the relative degree of thylakoid FA unsaturation and the related physiochemical properties of the thylakoid membrane, but rather raise potential alternative roles of long-chain polyunsaturated FAs during thermal stress. 
Table 1 Species-specific differences in symbiont density, chlorophyll concentrations and fatty acid content prior to the thermal stress experiment (day $0)$

\begin{tabular}{|c|c|c|c|}
\hline Parameter & Species effect & Tukey HSD & \\
\hline Symbiont density & $p<0.001$ & $(\mathrm{PdSt}=\mathrm{PdSy}) \neq \mathrm{Ph}$ & $p \leq 0.008$ \\
\hline chl $a\left(\right.$ pg cell $\left.^{-1}\right)$ & $p<0.001$ & $(\mathrm{PdSt}=\mathrm{PdSy}) \neq \mathrm{Ph}$ & $p \leq 0.002$ \\
\hline $\operatorname{chl} c_{2}\left(\mathrm{pg}\right.$ cell $\left.{ }^{-1}\right)$ & $p=0.004$ & $(\mathrm{PdSt}=\mathrm{PdSy}) \neq \mathrm{Ph}$ & $p \leq 0.043$ \\
\hline $\operatorname{chl} c_{2}: \operatorname{chl} a$ & $p=0.003$ & $(\mathrm{PdSt}=\mathrm{PdSy}) \neq \mathrm{Ph}$ & $p \leq 0.009$ \\
\hline SFA & $p=0.004$ & $(\mathrm{PdSt}=\mathrm{PdSy}) \neq \mathrm{Ph}$ & $p \leq 0.019$ \\
\hline $\mathrm{MUFA}^{\mathrm{NN}}$ & $p=0.005$ & $(\mathrm{PdSt}=\mathrm{PdSy}) \neq \mathrm{Ph}$ & $p \leq 0.019$ \\
\hline PUFA & $p<0.001$ & $(\mathrm{PdSt}=\mathrm{PdSy}) \neq \mathrm{Ph}$ & $p=0.001$ \\
\hline UFA:SFA & $p<0.001$ & $(\mathrm{PdSt}=\mathrm{PdSy}) \neq \mathrm{Ph}$ & $p<0.001$ \\
\hline$\Sigma \mathrm{C} 14$ & $p<0.001$ & $(\mathrm{PdSt}=\mathrm{PdSy}) \neq \mathrm{Ph}$ & $p<0.001$ \\
\hline$\Sigma \mathrm{C} 16$ & $p<0.001$ & $(\mathrm{PdSt}=\mathrm{PdSy}) \neq \mathrm{Ph}$ & $p<0.001$ \\
\hline$\Sigma \mathrm{C} 18$ & $p=0.124$ & & \\
\hline$\Sigma \mathrm{C} 20$ & $p<0.001$ & $(\mathrm{PdSt}=\mathrm{PdSy}) \neq \mathrm{Ph}$ & $p<0.001$ \\
\hline$\Sigma \mathrm{C} 22$ & $p=0.015$ & $(\mathrm{PdSt}=\mathrm{PdSy}) \neq \mathrm{Ph}$ & $p \leq 0.033$ \\
\hline
\end{tabular}

Results of univariate ANOVA with post hoc Tukey HSD, significant differences $(p \leq 0.05)$ are bolded. ${ }^{\mathrm{NN}}$ Results of univariate ANOVA were confirmed with the nonparametric Kruskal-Wallis test and post hoc Dunn-Bonferroni corrected pairwise comparison, as the assumption of normality was not met. SFA, relative content of saturated fatty acids; MUFA, relative content of mono-unsaturated fatty acids; PUFA, relative content of polyunsaturated fatty acids; UFA, unsaturated fatty acids; $\Sigma$ C14-22, fatty acids with aliphatic chains of 14-22 carbon atoms. PdSt, Pocillopora damicornis from Stephen's Hole; PdSy, Pocillopora damicornis from Sylph's Hole; PhSy, Porites heronensis from Sylph's Hole
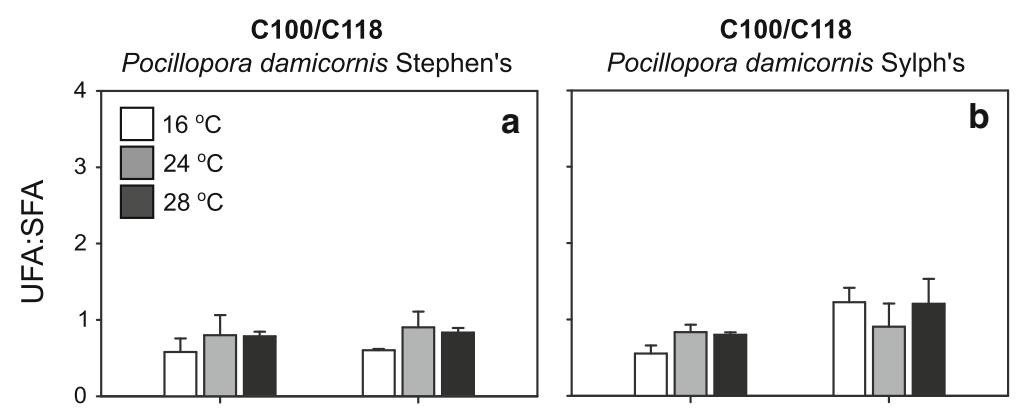

C111* Pocillopora heronensis Sylph's

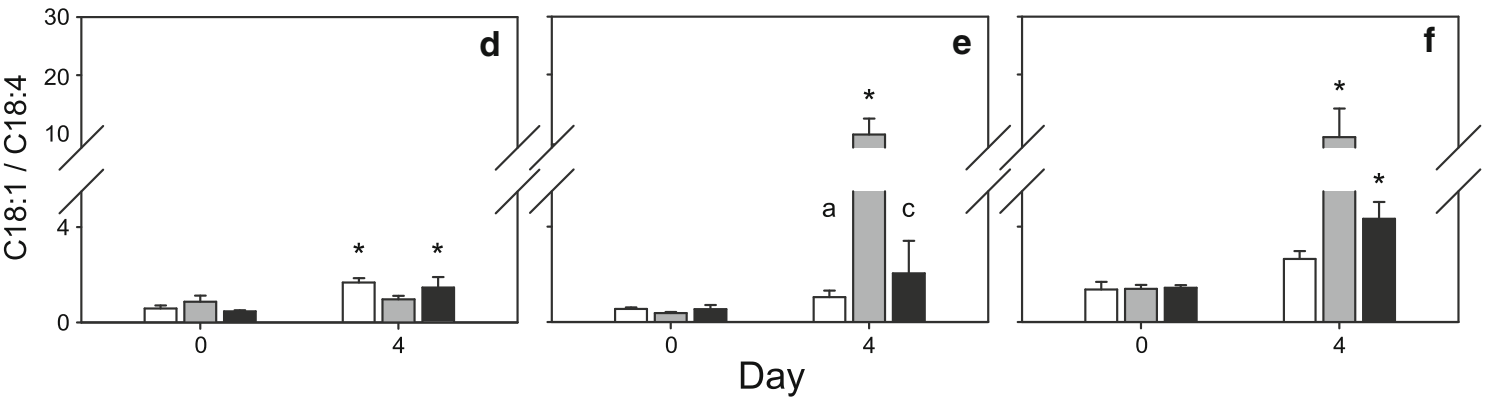

Fig. 3 Effect of temperature over a four-day period on the ratio of unsaturated fatty acids (UFAs) to saturated fatty acids (SFAs) (A-C) and ratio of $\mathrm{C} 18: 1$ (cis) to $\mathrm{C} 18: 4$. Values are means \pm S.E, $n=4$.

\section{Response to short-term cold stress}

Cold stress negatively affects photosynthesis in the Symbiodiniaceae and has been shown to result in lower quantum yields of chlorophyll fluorescence, to decrease the activities of enzymes involved in carbon fixation (Saxby et al. 2003; Thornhill et al. 2008; Roth et al. 2012; Oakley
Significant differences are a $16{ }^{\circ} \mathrm{C} v s .24{ }^{\circ} \mathrm{C}$, b $16{ }^{\circ} \mathrm{C} v s .28{ }^{\circ} \mathrm{C}$, and c $24{ }^{\circ} \mathrm{C} v s .28{ }^{\circ} \mathrm{C}$, and $(*)$ day 0 vs. day $4(p<0.05$, rmANOVA and pairwise comparison with Bonferroni correction)

et al. 2014), and to reduce membrane fluidity (Thornhill et al. 2008). Membrane fluidity is determined by properties of the FA chain constituents of thylakoid lipids and other membrane-stabilizing components (Guschina and Harwood 2006a). Membranes with a greater content of unsaturated, shorter, or branched FA chains are more fluid at a given temperature than are membranes with a higher content of 

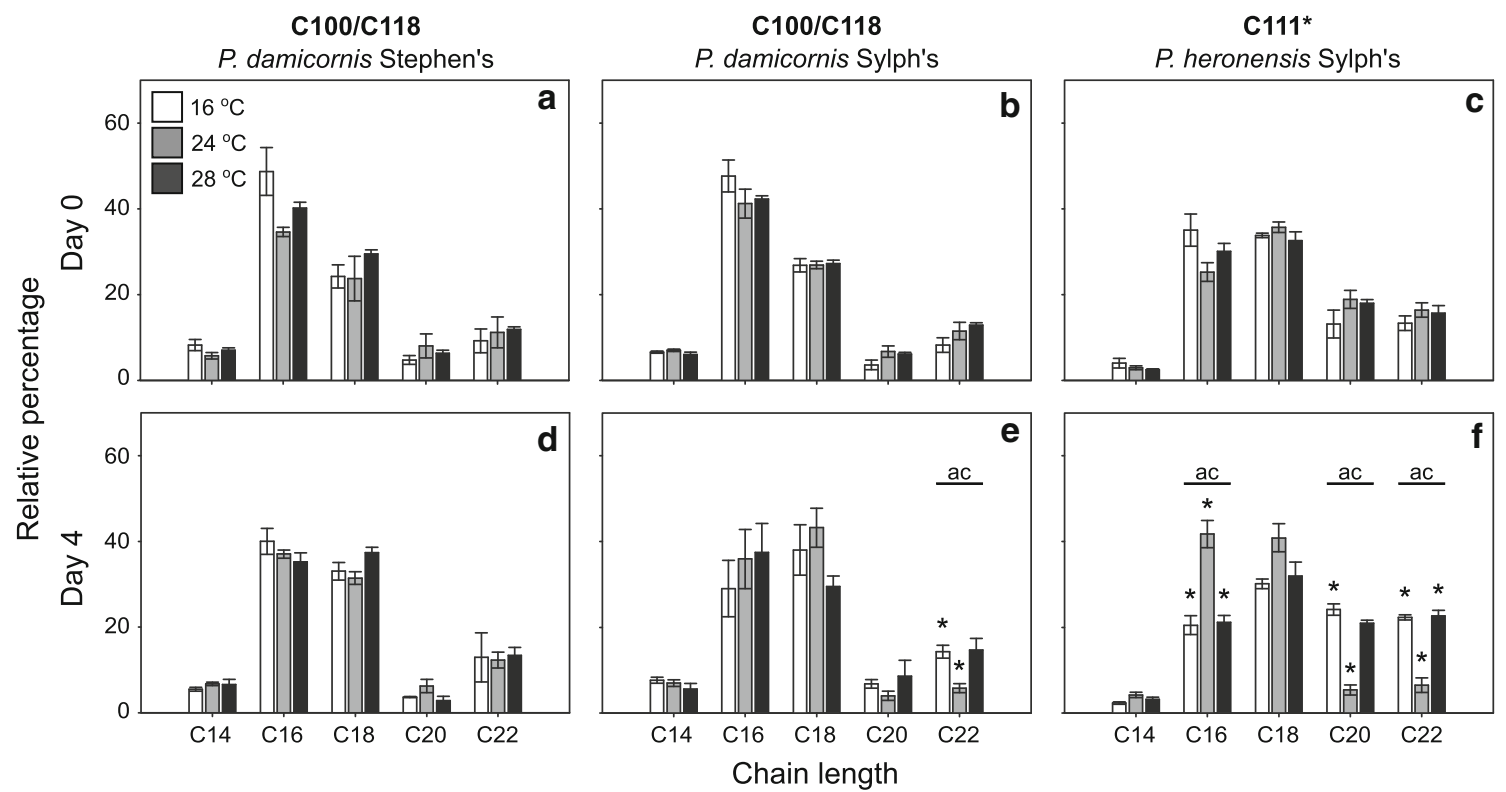

Fig. 4 Fatty acid composition by chain length on day 0 (a-c) and day 4 (d-f) of temperature treatment. Values are means \pm S.E, $n=4$. Significant differences are a $16{ }^{\circ} \mathrm{C}$ vs. $24{ }^{\circ} \mathrm{C}$, b $16{ }^{\circ} \mathrm{C}$ vs. $28^{\circ} \mathrm{C}$, and

saturated, longer or un-branched FA chains (Iba 2002; Morgan-Kiss et al. 2006). Increased FA unsaturation is a common acclimatory mechanism among many eukaryotes and is believed to counteract the increasing rigidity of membranes under cold stress, although the roles of highly unsaturated FAs may be more complex (Guschina and Harwood 2006b).

In this study, short-term cold stress caused substantial reductions in $F_{v} / F_{m}$ and increased excitation pressure over PSII $\left(Q_{m}\right)$ in all coral-symbiont associations (Fig. 2). No adverse effects of cold stress on pigment concentration or symbiont density were observed. Cladocopium $\mathrm{C} 111^{*}$ had a considerably higher relative content of baseline MUFAs and PUFAs than C100/C118 from either sampling location (Table 1). While the level of FA unsaturation increased in response to cold stress, $F_{v} / F_{m}$ of $\mathrm{C} 111^{*}$ was not enhanced over that of C100/C118 from Stephen's Hole (Figs. 3, 4). Taken together, the cold sensitivity of PSII was not associated with the overall membrane fluidity determined by FA unsaturation or chain length of the thylakoid FAs.

\section{Response to short-term heat stress}

None of the photophysiological parameters $F_{v} / F_{m}$, NPQ, $Q_{m}$, or pigment profile, nor symbiont density, were affected in any of the corals by short-term exposure to $3{ }^{\circ} \mathrm{C}$ above the typical bleaching threshold at Lord Howe Island $\left(25{ }^{\circ} \mathrm{C}\right.$, www.coralreefwatch.noaa.gov). Furthermore, thylakoid FA composition in Cladocopium C100/C118 did not change in response to heat stress (Fig. 4). Unexpectedly, c $24{ }^{\circ} \mathrm{C} v s .28{ }^{\circ} \mathrm{C}$, and $(*)$ day $0 v s$. day $4(p<0.05$, rmANOVA and pairwise comparison with Bonferroni correction)

under high temperature, Cladocopium $\mathrm{C} 111^{*}$ showed very similar dynamics of thylakoid membrane lipid elongation and desaturation to those seen under cold stress (Fig. 4). These modifications included those that would be expected to lower the melting point of the membranes: an overall reduction in the relative content of SFAs, mainly C16:0, and increases in the relative content of $\mathrm{C} 20$ and $\mathrm{C} 22$ PUFAs (Fig. 4). The relative content of the branched FA C18:1(n-9)cis increased, and C18:4(n-3) decreased, in both C111* and C100/C118 over time (Fig. 3, Tables S1-S3). This shift in the C18.1:C18:4 ratio is proposed to enhance the 'free volume' of the thylakoid bilayer and hence fluidity of the membrane (Heipieper et al. 2003). Tchernov et al. (2004) used this ratio to differentiate between thermally robust and sensitive symbiont strains. In their study, strains with a lower ratio of C18:1 to C18:4 exhibited losses of thylakoid integrity and photochemical efficiency and increased ROS concentrations compared to others. In contrast, Diaz-Almeyda et al. (2011) did not establish a correlation between the ratio of $\mathrm{C} 18: 1$ to $\mathrm{C} 18: 4$ and the melting point of the respective thylakoid membranes. Prolonged, severe thermal stress results first in thylakoid reorganization followed by loss of membrane integrity (Slavov et al. 2016). Here, exposure to $24{ }^{\circ} \mathrm{C}$, a moderate temperature for the local reef environment, resulted in a similar decrease in the relative content of C18:4 compared to C18:1 (Fig. 3), indicating that temperature-independent factors might be responsible for this adjustment. Heat stress resulted in a change of FA composition in $\mathrm{C} 111^{*}$, but 
whether this response improved thermal tolerance needs further exploration.

\section{Thylakoid fatty acid adjustments independent from thermal stress}

Thylakoid FAs were remodelled when exposed to $24{ }^{\circ} \mathrm{C}$, which corresponded to the sea surface temperature in the lagoon at the time of the experiment. The adjustments were evident in Cladocopium C100/C118 and C111* hosted by $P$. damicornis and P. heronensis from Sylph's Hole, but not in C100/C118 hosted by $P$. damicornis from Stephen's Hole. C100/C118 reduced its relative content of the PUFAs C18:4(n-3) and C22-6(n-3), while Cladocopium C111* reduced the relative content of all PUFAs and simultaneously increased the relative content of the SFAs C16:0 and C18:0 (Tables S1-3). The reduced PUFA and increased SFA levels may be a response to reduced nutrient availability, as Sylph's Hole can experience 1.8-fold increases in turbidity relative to Stephen's Hole (Wicks et al. 2010b). The flow-through lagoon seawater used for experimental incubation may have relatively low nutrient levels to Sylph's Hole, and limiting inorganic N or P results in lipid body growth in coral symbionts in hospite (Rosset et al. $2015,2017)$. A reduction in the relative content of the major PUFAs C18:4(n-3), C20:5(n-3), and C22:6(n-3) and an increase in the relative content of $\mathrm{C} 16: 0$ have also been observed in the total lipids of Gymnodinium sp. in response to nutrient limitation (Reitan et al. 1994).

The ability to adjust FA unsaturation or elongation in photosynthetic membranes in response to changes in temperature seems to be dependent on Cladocopium type and environmental conditions and history. This study demonstrates that, in Cladocopium $\mathrm{C} 111$ *, the responses of thylakoid FAs to short-term cold and heat stress are highly similar, suggesting a common mechanism to initiate these modifications. Increased levels of unsaturation did not enhance PSII capability under cold stress, nor impair PSII efficiency under heat stress. The absence of such correlation suggests that photosynthetic electron transport is unaffected, or at least not salvaged, by increased thylakoid FA unsaturation and membrane fluidity, as has been reported for cyanobacteria (Nanjo et al. 2010). Alternate hypotheses for the increased unsaturation of thylakoid membranes under thermal stress include the possibility that certain FAs may be required for the binding of membranestabilizing proteins (Takahashi et al. 2013). It has also been suggested that FA unsaturation could provide protection from oxidative stress in single-celled eukaryotes via the consumption of oxygen by the unsaturation reactions (Guerzoni et al. 2001). An increasing body of evidence suggests that PUFAs, especially C22:6(n-3) and C20:5(n3 ), are relatively unaffected by oxidative damage in vivo
(Araseki et al. 2005; Okuyama et al. 2008) and may provide an antioxidant function by absorbance of photosynthetic ROS (Schmid-Siegert et al. 2016). In Cladocopium C111*, C20:5(n-3), alongside other PUFAs, increased in response to both cold and heat stress (Table S3). If the synthesis of $\mathrm{C} 20: 5(n-3)$ is photoprotective, via the utilization of excess electrons, then one might expect a lower pressure over the photosystem, which was not evident. The simultaneous analysis of FA composition, intracellular ROS concentrations and lipid peroxidation would be greatly informative to assess the importance of PUFAs in controlling oxidative stress. Targeted study of the processes and pathways induced by both high- and low-temperature stress may reveal common sensory and response mechanisms and provide greater detail on the thermal resilience of dinoflagellate symbionts.

Supplementary Information The online version contains supplementary material available at https://doi.org/10.1007/s00338022-02221-2.

Acknowledgements We thank I. Kerr, S. Gudge (Marine Park Authority, Lord Howe Island) and B. Busteed (Howea Divers) for field and logistical support, and A. Salih for equipment.

Funding Open Access funding enabled and organized by CAUL and its Member Institutions. Financial support for this research was provided by the Marsden Fund of the Royal Society Te Apārangi, Grant number VUW0902, to S.K.D., S.D., P.L.F., O.H-G. and W.L. and research funds from the School of Biological Sciences at Te Herenga Waka Victoria University of Wellington.

\section{Declarations}

Conflict of interest On behalf of all authors, the corresponding author states that there is no conflict of interest.

Open Access This article is licensed under a Creative Commons Attribution 4.0 International License, which permits use, sharing, adaptation, distribution and reproduction in any medium or format, as long as you give appropriate credit to the original author(s) and the source, provide a link to the Creative Commons licence, and indicate if changes were made. The images or other third party material in this article are included in the article's Creative Commons licence, unless indicated otherwise in a credit line to the material. If material is not included in the article's Creative Commons licence and your intended use is not permitted by statutory regulation or exceeds the permitted use, you will need to obtain permission directly from the copyright holder. To view a copy of this licence, visit http://creativecommons. org/licenses/by/4.0/.

\section{References}

Araseki M, Kobayashi H, Hosokawa M, Miyashita K (2005) Lipid peroxidation of a human hepatoma cell line (HepG2) after incorporation of linoleic acid, arachidonic acid, and docosahexaenoic acid. Biosci Biotechnol Biochem 69:483-490

Berkelmans R, van Oppen MJ (2006) The role of zooxanthellae in the thermal tolerance of corals: a 'nugget of hope' for coral reefs in an era of climate change. Proc R Soc B Biol Sci 273:2305-2312 
Bishop DG, Kenrick JR (1980) Fatty acid composition of symbiotic zooxanthellae in relation to their hosts. Lipids 15:799-804

Davy SK, Allemand D, Weis VM (2012) Cell biology of cnidariandinoflagellate symbiosis. Microbiol Mol Biol Rev 76:229-261

Díaz-Almeyda E, Thomé PE, El Hafidi M, Iglesias-Prieto R (2011) Differential stability of photosynthetic membranes and fatty acid composition at elevated temperature in Symbiodinium. Coral Reefs 30:217-225

Dimond JL, Bingham BL, Muller-Parker G, Oakley CA (2013) Symbiont physiology and population dynamics before and during symbiont shifts in a flexible algal-cnidarian symbiosis. J Phycol 49:1074-1083

Fisher PL, Malme MK, Dove S (2012) The effect of temperature stress on coral-Symbiodinium associations containing distinct symbiont types. Coral Reefs 31:473-485

Folch J, Lees M, Stanley GH (1957) A simple method for the isolation and purification of total lipides from animal tissues. J Biol Chem 226:497-509

Guerzoni ME, Lanciotti R, Cocconcelli PS (2001) Alteration in cellular fatty acid composition as a response to salt, acid, oxidative and thermal stresses in Lactobacillus helveticus. Microbiology 147:2255-2264

Guschina IA, Harwood JL (2006a) Lipids and lipid metabolism in eukaryotic algae. Prog Lipid Res 45:160-186

Guschina IA, Harwood JL (2006b) Mechanisms of temperature adaptation in poikilotherms. FEBS Lett 580:5477-5483

Heipieper HJ, Meinhardt F, Segura A (2003) The cis-trans isomerase of unsaturated fatty acids in Pseudomonas and Vibrio: biochemistry, molecular biology and physiological function of a unique stress adaptive mechanism. FEMS Microbiol Lett 229:1-7

Hennige SJ, Suggett DJ, Warner ME, McDougall KE, Smith DJ (2008) Photobiology of Symbiodinium revisited: bio-physical and bio-optical signatures. Coral Reefs 28:179-195

Hillyer KE, Dias DA, Lutz A, Roessner U, Davy SK (2017a) Mapping carbon fate during bleaching in a model cnidarian symbiosis: the application of ${ }^{13} \mathrm{C}$ metabolomics. New Phytol 214:1551-1562

Hillyer KE, Dias DA, Lutz A, Wilkinson SP, Roessner U, Davy SK (2017b) Metabolite profiling of symbiont and host during thermal stress and bleaching in the coral Acropora aspera. Coral Reefs 36:105-118

Hoegh-Guldberg O (1999) Climate change, coral bleaching and the future of the world's coral reefs. Mar Fresh Res 50:839-866

Hoegh-Guldberg O, Fine M (2004) Low temperatures cause coral bleaching. Coral Reefs 23:444-444

Hughes TP, Kerry J, Álvarez-Noriega M, Álvarez-Romero J, Anderson K, Baird A, Babcock R, Beger M, Bellwood D, Berkelmans R, Bridge T, Butler I, Byrne M, Cantin N, Comeau S, Connolly S, Cumming G, Dalton S, Diaz-Pulido G, Eakin CM, Figueira W, Gilmour J, Harrison H, Heron S, Hoey AS, Hobbs J-P, Hoogenboom M, Kennedy E, Kuo C-Y, Lough J, Lowe R, Liu G, Malcolm McCulloch HM, McWilliam M, Pandolfi J, Pears R, Pratchett M, Schoepf V, Simpson T, Skirving W, Sommer B, Torda G, Wachenfeld D, Willis B, Wilson S (2017) Global warming and recurrent mass bleaching of corals. Nature 543:373-378

Hughes TP, Anderson KD, Connolly SR, Heron SF, Kerry JT, Lough JM, Baird AH, Baum JK, Berumen ML, Bridge TC, Claar DC, Eakin CM, Gilmour JP, Graham NAJ, Harrison H, Hobbs J-PA, Hoey AS, Hoogenboom M, Lowe RJ, McCulloch MT, Pandolfi JM, Pratchett M, Schoepf V, Torda G, Wilson SK (2018) Spatial and temporal patterns of mass bleaching of corals in the Anthropocene. Science 359:80-83

Iba K (2002) Acclimative response to temperature stress in higher plants: approaches of gene engineering for temperature tolerance. Annu Rev Plant Biol 53:225-245
Iglesias-Prieto R, Beltran VH, LaJeunesse TC, Reyes-Bonilla H, Thome PE (2004) Different algal symbionts explain the vertical distribution of dominant reef corals in the eastern Pacific. Proc $\mathrm{R}$ Soc L B 271:1757-1763

Jeffrey SW, Humphrey GF (1975) New spectrophotometric equations for determining chlorophylls $a, b, c_{1}$ and $c_{2}$ in higher plants, algae and natural phytoplankton. Biochem Und Physiol Der Pflanz 167:191-194

Kemp DW, Oakley CA, Thornhill DJ, Newcomb LA, Schmidt GW, Fitt WK (2011) Catastrophic mortality on inshore coral reefs of the Florida Keys due to severe low-temperature stress. Glob Chang Biol 17:3468-3477

LaJeunesse TC (2002) Diversity and community structure of symbiotic dinoflagellates from Caribbean coral reefs. Mar Biol 141:387-400

LaJeunesse TC, Pettay DT, Sampayo EM, Phongsuwan N, Brown B, Obura DO, Hoegh-Guldberg O, Fitt WK (2010) Long-standing environmental conditions, geographic isolation and host-symbiont specificity influence the relative ecological dominance and genetic diversification of coral endosymbionts in the genus Symbiodinium. J Biogeogr 37:785-800

LaJeunesse TC, Parkinson JE, Gabrielson PW, Jeong HJ, Reimer JD, Voolstra CR, Santos SR (2018) Systematic revision of Symbiodiniaceae highlights the antiquity and diversity of coral endosymbionts. Curr Biol 28:2570-2580.e6

LaJeunesse TC, Wiedenmann J, Casado-Amezúa P, D’Ambra I, Turnham KE, Nitschke MR, Oakley CA, Goffredo S, Spano CA, Cubillos VM, Davy SK, Suggett DJ (2021) Revival of Philozoon Geddes for host-specialized dinoflagellates, 'zooxanthellae', in animals from coastal temperate zones of northern and southern hemispheres. Eur J Phycol 00:1-15

Mansour MP, Volkman JK, Jackson AE, Blackburn SI (1999) The fatty acid and sterol composition of five marine dinoflagellates. J Phycol 35:710-720

Mansour JS, Pollock FJ, Diaz-Almeyda E, Iglesias-Prieto R, Medina $M$ (2018) Intra- and interspecific variation and phenotypic plasticity in thylakoid membrane properties across two Symbiodinium clades. Coral Reefs 37:841-850

Matthews JL, Crowder CM, Oakley CA, Lutz A, Roessner U, Meyer E, Grossman AR, Weis VM, Davy SK (2017) Optimal nutrient exchange and immune responses operate in partner specificity in the cnidarian-dinoflagellate symbiosis. Proc Natl Acad Sci 114:13194-13199

Matthews JL, Oakley CA, Lutz A, Hillyer KE, Roessner U, Grossman AR, Weis VM, Davy SK (2018) Partner switching and metabolic flux in a model cnidarian-dinoflagellate symbiosis. Proc R Soc B Biol Sci 285:20182336

Morgan-Kiss RM, Priscu JC, Pocock T, Gudynaite-savitch L, Huner NPA (2006) Adaptation and acclimation of photosynthetic microorganisms to permanently cold environments. Microbiol Mol Biol Rev 70:222-252

Mullineaux CW, Kirchhoff H (2009) Role of lipids in the dynamics of thylakoid membranes. In: Wada $\mathrm{H}$, Murata $\mathrm{N}$ (eds) Lipids in photosynthesis: essential and regulatory functions. Springer, Netherlands, Dordrecht, pp 283-294

Nanjo Y, Mizusawa N, Wada H, Slabas AR, Hayashi H, Nishiyama Y (2010) Synthesis of fatty acids de novo is required for photosynthetic acclimation of Synechocystis sp. PCC 6803 to high temperature. Biochim Biophys Acta - Bioenerg 1797:1483-1490

Nitschke MR, Craveiro SC, Brandão C, Fidalgo C, Serôdio J, Calado AJ, Frommlet JC (2020) Description of Freudenthalidium gen. nov. and Halluxium gen. nov. to formally recognize clades Fr3 and $\mathrm{H}$ as genera in the family Symbiodiniaceae (Dinophyceae). J Phycol 56:923-940 
NOAA Coral Reef Watch (2018) NOAA Coral reef watch version 3.1 daily $5 \mathrm{~km}$ satellite regional virtual station time series data for eastern red sea, Nov. 25, 2019-Jan. 18, 2021. Silver Spring, Maryland, USA

Oakley CA, Davy SK (2018) Cell biology of coral bleaching. In: van Oppen M, Lough J (eds) coral bleaching. Springer, Berlin, pp 189-211

Oakley CA, Schmidt GW, Hopkinson BM (2014) Thermal responses of Symbiodinium photosynthetic carbon assimilation. Coral Reefs 33:501-512

Okuyama H, Orikasa Y, Nishida T (2008) Significance of antioxidative functions of eicosapentaenoic and docosahexaenoic acids in marine microorganisms. Appl Environ Microbiol 74:570-574

Papina M, Meziane T, van Woesik R (2007) Acclimation effect on fatty acids of the coral Montipora digitata and its symbiotic algae. Comp Biochem Physiol Part B Biochem Mol Biol 147:583-589

Pettay DT, Wham DC, Smith RT, Iglesias-Prieto R, LaJeunesse TC (2015) Microbial invasion of the Caribbean by an Indo-Pacific coral zooxanthella. Proc Natl Acad Sci 112:201502283

Pochon X, LaJeunesse TC (2021) Miliolidium n. gen, a new Symbiodiniacean genus whose members associate with soritid foraminifera or are free-living. J Eukaryot Microbiol 68:1-9

Pochon X, Pawlowski J, Zaninetti L, Rowan R (2001) High genetic diversity and relative specificity among Symbiodinium-like endosymbiotic dinoflagellates in soritid foraminiferans. Mar Biol 139:1069-1078

Pontasch S, Fisher PL, Krueger T, Dove S, Leggat W, Davy SK (2017) Photoacclimatory and photoprotective responses to cold versus heat stress in high latitude reef corals. J Phycol 53:308-321

Reitan KI, Rainuzzo JR, Olsen Y (1994) Effect of nutrient limitation on fatty acid and lipid content of marine microalgae. J Phycol 30:972-979

Ritchie RJ (2006) Consistent sets of spectrophotometric chlorophyll equations for acetone, methanol and ethanol solvents. Photosynth Res 89:27-41

Rosset S, D'Angelo C, Wiedenmann J (2015) Ultrastructural biomarkers in symbiotic algae reflect the availability of dissolved inorganic nutrients and particulate food to the reef coral holobiont. Front Mar Sci 2:1-10

Rosset S, Wiedenmann J, Reed AJ, D'Angelo C (2017) Phosphate deficiency promotes coral bleaching and is reflected by the ultrastructure of symbiotic dinoflagellates. Mar Pollut Bull 118:180-187

Rosset SL, Oakley CA, Ferrier-Pagès C, Suggett DJ, Weis VM, Davy SK (2021) The molecular language of the cnidarian-dinoflagellate symbiosis. Trends Microbiol 29:320-333

Roth MS, Goericke R, Deheyn DD (2012) Cold induces acute stress but heat is ultimately more deleterious for the reef-building coral Acropora yongei. Sci Rep 2:240

Saxby T, Dennison W, Hoegh-Guldberg O (2003) Photosynthetic responses of the coral Montipora digitata to cold temperature stress. Mar Ecol Prog Ser 248:85-97

Schmid-Siegert E, Stepushenko O, Glauser G, Farmer EE (2016) Membranes as structural antioxidants recycling of malondialdehyde to its source in oxidation-sensitive chloroplast fatty acids. J Biol Chem 291:13005-13013

Schrameyer V, Wangpraseurt D, Hill R, Kühl M, Larkum AWD, Ralph PJ (2014) Light respiratory processes and gross photosynthesis in two scleractinian corals. PLoS One 9:e110814

Slavov C, Schrameyer V, Reus M, Ralph PJ, Hill R, Büchel C, Larkum AWD, Holzwarth AR (2016) "Super-quenching" state protects Symbiodinium from thermal stress - implications for coral bleaching. Biochim Biophys Acta - Bioenerg 1857:840-847
Sproles AE, Oakley CA, Matthews JL, Peng L, Owen JG, Grossman AR, Weis VM, Davy SK (2019) Proteomics quantifies protein expression changes in a model cnidarian colonised by a thermally tolerant but suboptimal symbiont. ISME J 13:2334-2345

Stat M, Pochon X, Cowie R, Gates R (2009) Specificity in communities of Symbiodinium in corals from Johnston Atoll. Mar Ecol Prog Ser 386:83-96

Stimson J, Kinzie RA (1991) The temporal pattern and rate of release of zooxanthellae from the reef coral Pocillopora damicornis (Linnaeus) under nitrogen-enrichment and control conditions. J Exp Mar Bio Ecol 153:63-74

Suggett DJ, Goyen S, Evenhuis C, Szabó M, Pettay DT, Warner ME, Ralph PJ (2015) Functional diversity of photobiological traits within the genus Symbiodinium appears to be governed by the interaction of cell size with cladal designation. New Phytol 208:370-381

Swain TD, Chandler J, Backman V, Marcelino L (2017) Consensus thermotolerance ranking for 110 Symbiodinium phylotypes: an exemplar utilization of a novel iterative partial-rank aggregation tool with broad application potential. Funct Ecol 31:172-183

Takahashi S, Yoshioka-Nishimura M, Nanba D, Badger MR (2013) Thermal acclimation of the symbiotic alga Symbiodinium spp. Alleviates photobleaching under heat stress. Plant Physiol 161:477-485

Tchernov D, Gorbunov MY, de Vargas C, Narayan Yadav S, Milligan AJ, Häggblom M, Falkowski PG (2004) Membrane lipids of symbiotic algae are diagnostic of sensitivity to thermal bleaching in corals. Proc Natl Acad Sci U S A 101:13531-13535

Thornhill DJ, Kemp DW, Bruns BU, Fitt WK, Schmidt GW (2008) Correspondence between cold tolerance and temperate biogeography in a Western Atlantic Symbiodinium (Dinophyta) lineage. J Phycol 44:1126-1135

Ulstrup KE, Ralph PJ, Larkum AWD, Kühl M (2006) Intra-colonial variability in light acclimation of zooxanthellae in coral tissues of Pocillopora damicornis. Mar Biol 149:1325-1335

Ulstrup KE, Ralph PJ, Hill R (2009) Temperature induced changes in thylakoid membrane thermostability of cultured, freshly isolated, and expelled zooxanthellae from scleractinian corals. Bull Mar Sci 85:223-244

Warner ME, Suggett DJ (2016) The photobiology of Symbiodinium spp.: linking physiological diversity to the implications of stress. In: Goffredo S, Dubinsky Z (eds) The cnidaria, past, present and future: the world of Medusa and her sisters. Springer Publishing, Berlin, pp 489-509

Warner ME, Fitt WK, Schmidt GW (1996) The effects of elevated temperature on the photosynthetic efficiency of zooxanthellae in hospite from four different species of reef coral: a novel approach. Plant Cell Environ 19:291-299

Wicks LC, Hill R, Davy SK (2010a) The influence of irradiance on tolerance to high and low temperature stress exhibited by Symbiodinium in the coral, Pocillopora damicornis, from the high-latitude reef of Lord Howe Island. Limnol Oceanogr 55:2476-2486

Wicks LC, Sampayo E, Gardner JPA, Davy SK (2010b) Local endemicity and high diversity characterise high-latitude coralSymbiodinium partnerships. Coral Reefs 29:989-1003

Zhukova NV, Titlyanov EA (2003) Fatty acid variations in symbiotic dinoflagellates from Okinawan corals. Phytochemistry 62:191-195

Zhukova NV, Titlyanov EA (2006) Effect of light intensity on the fatty acid composition of dinoflagellates symbiotic with hermatypic corals. Bot Mar. 49:339-346

Publisher's Note Springer Nature remains neutral with regard to jurisdictional claims in published maps and institutional affiliations. 